\title{
SPECIFIC FAILURES OF SUPERALLOYS WITH THERMAL BARRIER COATINGS SUBJECTED TO THERMO-MECHANICAL FATIGUE LOADINGS WITH A THERMAL GRADIENT IN A SIMULATED COMBUSTION ENVIRONMENT
}

\author{
Masakazu Okazaki ${ }^{1}$, Satoshi Yamagishi ${ }^{1}$, Motoki Sakaguchi ${ }^{1}$, Subramanian Rajivgandhi ${ }^{1}$ \\ ${ }^{1}$ Department of Mechanical Engineering, Nagaoka University of Technology, \\ 1603-1 Kamitomiokamachi, Nagaoka-shi, Niigata 940-2188, Japan \\ E-mail: okazaki@mech.nagaokaut.ac.jp
}

Key Words: Thermo-mechanical fatigue, MAR-M 247, IN738, Thermal barrier coatings, Damage map, Ratcheting

\begin{abstract}
$\underline{\text { Abstract }}$
A new test system has been developed which enables us to apply complicated thermo-mechanical fatigue (TMF) loadings to superalloy specimens in order to simulate the conditions and significant temperature gradients that are experienced in components that operate in a combustion gas flow environment. Employing this system, some TMF tests were carried out for superalloy specimens with thermal barrier coatings (TBCs) under a combined condition in which the external load was superimposed on the thermal cycles. Here, special attention was paid to the specific damage morphologies and the deformation under this kind of complicated TMF loadings. Based on the experimental results, a new mechanistic model was proposed for the specific failure modes, especially for a creep-induced ratcheting phenomenon as well as for failures of ceramic top coat. Finally, this understanding is summarized in a damage map, which is defined in terms of some mechanical criteria.
\end{abstract}

\section{$\underline{\text { Introduction }}$}

Development of high performance superalloys and their structures have been core technology to improve the performance and the efficiency of advanced gas turbines, which are in service at extremely high temperatures [1-8]. To ensure the reliability of coated superalloy components, it is necessary to understand many kinds of damage mechanisms such as creep, fatigue, thermomechanical fatigue and so on. Nowadays the basic principles of these failures seem to have been understood under idealized laboratory conditions, so far as they are solely contributing in a simple manner. One of factors to be concerned is their interactions and failures under more complicated conditions. Thermomechanical fatigue (TMF) failure is one of such representative phenomena [10-12], where the stress due to external loads is superimposed on the internal stress field that results from thermal cycles that are not always in phase with the imposed external load.

Meanwhile thermally insulating ceramic coatings, known as thermal barrier coatings (TBCs) are increasingly more important year by year. The key role of TBCs is, of course, to protect the metal substrate from high temperature oxidation and environmental attack. This has been often achieved by coating the substrate with a ceramic top coat which exhibits a lower thermal conductivity than the superalloy $[1,2]$. The most critical issue limiting durability of TBCs is spallation of the ceramic top coat. Once this type of damage occurs, hot section components made of a superalloy substrate may be overheated, resulting in complete failure. In general the TBC system consists of at least three layers; ceramic top coat, bond coat and metal substrate: thus, thermal or internal stress resulting from the mismatches in thermal expansion coefficient and thermal conductivities between them plays an intrinsic role, even when no external load is applied. In addition the influence of environment, i.e. formation of thermally grown oxides (TGO) at the bond coat/top coat interface, may promote the evolution of damage [1-3,8]. It is not difficult to postulate that when the external stress or load is superimposed on the thermal cycles, the damage rate must be significantly accelerated. In the other words, knowledge of TMF failures of the TBCs is critical in understanding component reliability. Nevertheless, a detailed analysis of the mechanisms and the possibilities of avoiding damage is still lacking [1-10].

Since the superalloys with TBCs are subject to high temperatures and significant temperature gradients in service, an understanding of the effects of complicated TMF cycles on damage evolution is required. The level of understanding is quite limited and can be improved. Nevertheless, understandings are quite limited. A lack of adequate test beds for the purpose makes difficult. Burner rigs [10] are often used to simulate combustion gas conditions but the usefulness of these test beds would be improved if external loads could be applied.

Based on these limitations, a new test system has been developed in this work so that the TMF loadings can be superimposed on the thermal cycles under a significant temperature gradient inside the specimen in an actual combustion gas flow environment. By means of the test system developed, TMF tests were carried out for the superalloy TBC specimens. Special attention was paid to the specific damage morphologies and the evolution process, comparing with those under normal test conditions without temperature gradients.

\section{The Development and Performance of a New Test System}

A new test facility illustrated in Figure 1 has been developed in this work, where the system consists of the combustor part and the test section. In the former, a simulated combustion atmosphere is produced employing a can type of combustor, so that the test section inlet temperature (TSIT) reaches a maximum of $1500{ }^{\circ} \mathrm{C}$, with a maximum combustion gas velocity of $50 \mathrm{~m} / \mathrm{sec}$. The main fuel used is methane gas; so-called $13 \mathrm{~A}$ gas. In the latter, a servohydraulic testing machine is installed so that a thermo-mechanical fatigue loading can be applied to the superalloy specimens in a synchronized manner with thermal cycles of TSIT $[9,10]$. 


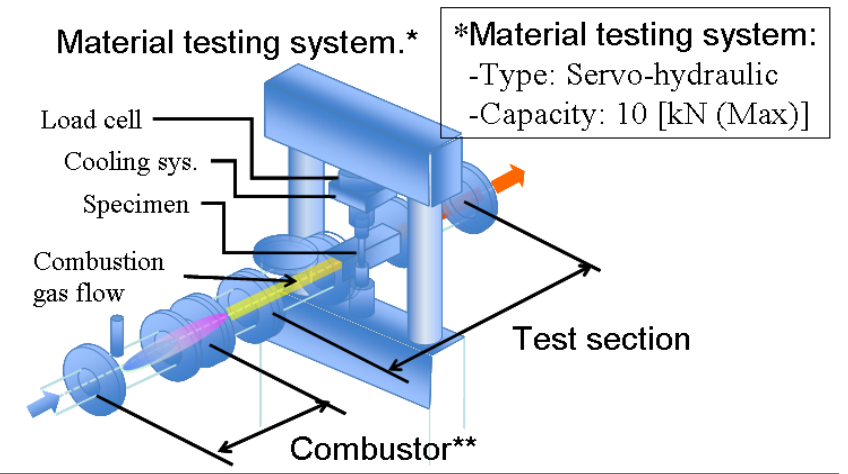

${ }^{\star \star}$ Combustion system.

-Fuel: Natural gas; -Test section inlet temp.: 600 1500 [C]

-Maximum gas velocity: $50[\mathrm{~m} / \mathrm{s}]$; -Gas pressure: $0.7[\mathrm{kPa}]$

Figure 1. Illustration of a new test system developed.

Table I. Summary of temperature gradients at representative parts inside the TBC specimen when thermal cycles were applied between $1280 / 700^{\circ} \mathrm{C}$ (in TSIT) using the new test facility.

\begin{tabular}{l|c|c|c|c|c|c}
\hline & \multicolumn{2}{|c|}{ Uptream } & \multicolumn{2}{c|}{ Side } & \multicolumn{2}{c}{ Downstream } \\
\hline $\begin{array}{l}\text { Test section Inlet } \\
\text { gas temperature } \\
\star\end{array}$ & $\begin{array}{l}\text { Gas temp. } \\
\text { above TBC } \\
\text { specimen } \\
\text { surface }\left({ }^{\circ} \mathrm{C}\right)\end{array}$ & $\begin{array}{l}\text { Interface } \\
\text { temp. in TBC } \\
\text { specimen } \\
\left({ }^{\circ} \mathrm{C}\right)\end{array}$ & $\begin{array}{l}\text { Gas temp. } \\
\text { above TBC } \\
\text { specimen } \\
\text { surface }\left({ }^{\circ} \mathrm{C}\right)\end{array}$ & $\begin{array}{l}\text { Interface } \\
\text { temp. in TBC } \\
\text { specimen } \\
\left({ }^{\circ} \mathrm{C}\right)\end{array}$ & $\begin{array}{l}\text { Gas temp. } \\
\text { above TBC } \\
\text { specimen } \\
\text { surface }\left({ }^{\circ} \mathrm{C}\right)\end{array}$ & $\begin{array}{l}\text { Interface } \\
\text { temp. in TBC } \\
\text { specimen }\left({ }^{\circ} \mathrm{C}\right)\end{array}$ \\
\hline 1280 & 1055 & 1015 & 1022 & 988 & 977 & 961 \\
\hline 700 & 575 & 551 & 557 & 545 & 537 & 529 \\
\hline
\end{tabular}

* Changed cyclically with a frequency of $180 / 180 \mathrm{sec}$. in heating/cooling time respectively.

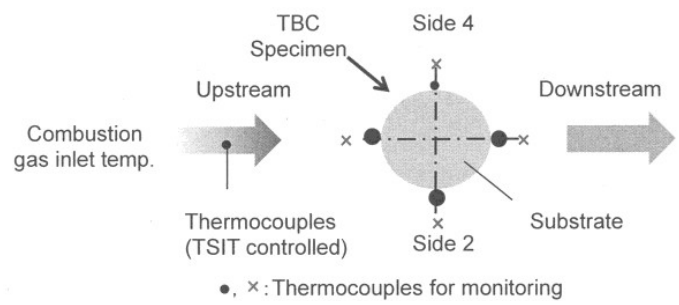

As described later, the test temperature was controlled by the TSIT. This implies, the temperatures inside of the TBC specimen is not equal to TSIT. In order to know the temperature gradient inside of the specimen during the TMF test, the temperature of the ceramic top coat was continuously monitored via four B type thermocouples directly mounted by zirconia cement; they were located at upstream and downstream positions in combustion gas flow (see an illustration in Table I). Before the actual TMF testing, the inside temperature of the TBC specimen was also measured at the top bond coat/substrate interface, by applying the thermal cycles same as the TMF test condition. In this case the thermocouples were previously welded through the small holes in the top coat (note, the holes were filled again by a zirconia cement before the measurement).

Figure 2 displays a temperature history at the bond coat /substrate interfaces in the coated specimen used in this work (that will be shown later), in which the specimen was exposed to the same thermal cycles as the actual TMF test between TSITs of $1280 / 700{ }^{\circ} \mathrm{C}$ with a frequency of $180 / 180 \mathrm{sec}$. in heating/cooling

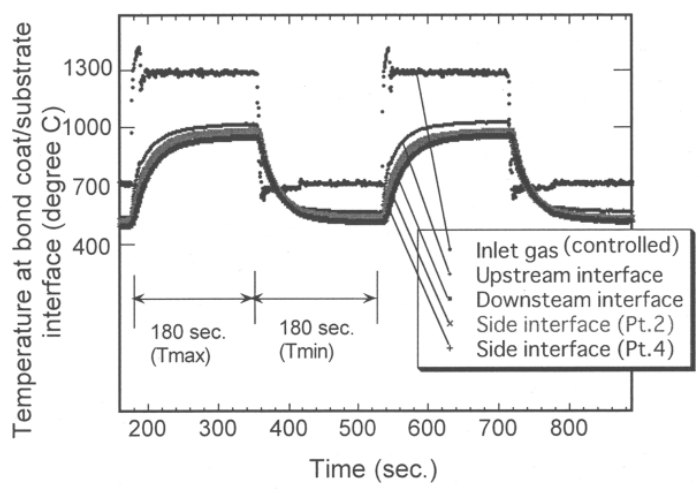

Figure 2. Thermal history at the representative interfaces when thermal cycles between $1280 / 700^{\circ} \mathrm{C}$ (in TSIT) were applied using the new test facility.

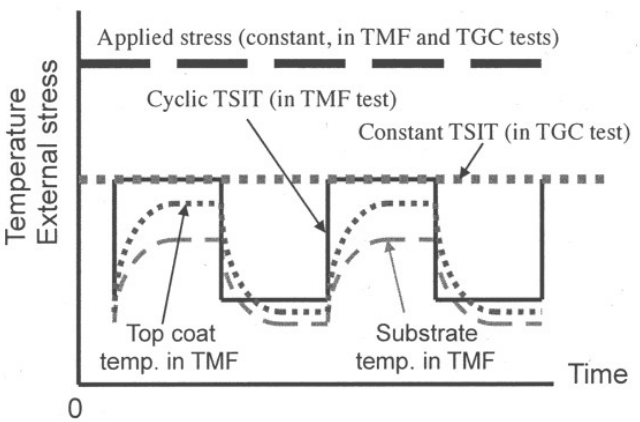

Figure 3. Illustration of the present TMF test.

duration time; see Figure 3. It is found from Figure 2 that a significant temperature gradient is produced inside the TBC specimen by the present new test facilities. It is found from Figure 2 and Table I that the temperature gradient through the top coat thickness were as follows, when the TSIT was set to $1280{ }^{\circ} \mathrm{C}$, or, maximum gas temperature in the present TMF test: it is approximately $80{ }^{\circ} \mathrm{C} / \mathrm{mm}$ at the upstream position and $40{ }^{\circ} \mathrm{C} / \mathrm{mm}$ at the downstream position, respectively. In the other words, the gradient was higher at the former position. Note that there was also a significant temperature gradient inside the metal substrate between the upstream and downstream (Table I). When the TSIT was set to $750{ }^{\circ} \mathrm{C}$, or, the lower gas temperature in the TMF test, on the other hand, the gradient was less pronounced (see Table I).

The temperature gradients summarized in Table 1 depend on the condition: e.g., how high the TSIT is, as well as the value of the thermal cycle frequency. These important factors can be varied in the present test facilities. TSIT can reach a maximum temperature of $1500{ }^{\circ} \mathrm{C}$. In addition, external load can be arbitrary applied to the specimens through the servo-hydraulic loading system so that it is superimposed on the thermal cycles in a controlled manner. The essence of this kind of TMF testing method follows more conventional TMF testing $[9,10]$.

\section{Experimental Procedure}

Solid cylindrical TBC specimens as shown in Figure 4 were prepared in this work, where the substrate alloy was either Mar-M 
247 or IN738 polycrystalline Ni-based alloy. Before the thermal coating was applied, the substrate received a solution treatment of $1180 \mathrm{C}$ for $2 \mathrm{hrs}$., followed by an aging treatment of $1080{ }^{\circ} \mathrm{C}$ for $24 \mathrm{hrs}$. The present TBC specimen is composed of three layers; Nibase superalloy, bond coat (CoNiCrAlY alloy (AMDRY 9951), and ceramic top coat. The chemical compositions of the original powders used are summarized in Table II. These TBC specimens were fabricated as follows: after spraying the bond coat alloy to $100 \mu m$ in thickness on the substrate using low pressure plasma spraying, the YSZ top coat was overlay coated to $500 \mu \mathrm{m}$ in thickness using atmospheric plasma spraying. These processes were performed by Plasma Giken Co. Ltd., Japan. The details are presented in Ref. 11.

Three kinds of tests were carried in this work according to the test program in Table III. These tests were $T M F$ test, "thermally gradient creep" (TGC) test, and creep test. The first TMF tests were carried out, employing the new testing system documented. Unless utherwise stated, the thermal cycles were applied between maximum TSIT (Tmax) and minimum TSIT (Tmin) in a linear fashion over a time of $360 \mathrm{sec}$. Temperatures were maintained at Tmax and Tmin for a period of $180 \mathrm{sec}$., respectively. Note that this type of thermal cycle introduced between about 1015 and $550{ }^{\circ} \mathrm{C}$ in the superalloy substrate, and between about 1055 and $575{ }^{\circ} \mathrm{C}$ in the ceramic top coat at the specimen upstream side, which confirms the temperature gradient shown in Table I. In the present TMF test a static, or constant axial stress was superimposed on these thermal cycles in order to simulate a centrifugal force to which gas turbine blades are subjected (Figure 3 and Table III). The magnitude of axial stress applied was an experimental variable in the present TMF tests; that was 0,70 , 100 and $170 \mathrm{MPa}$ in tension.

In the $T G C$ test an axial constant stress was applied to the specimen by means of the same testing system as that was used for the TMF tests, where the test temperature was controlled by TSIT. Note that no thermal cycles were repeated in the $T G C$ : the TSIT was kept constant at $1280{ }^{\circ} \mathrm{C}$, while there was a temperature gradient inside the specimen which creates thermal stresses.

For the purpose of comparison with the above two tests, a simple creep test was also carried out at constant temperature in laboratory air; see Table III. Here the specimen was heated at $990{ }^{\circ} \mathrm{C}$ by means of an induction heating system, which provided

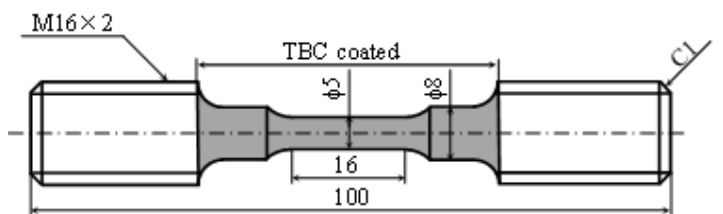

Figure 4. Geometry of specimen used (dimensions are given by substrate part in $\mathrm{mm}$ ). The ceramic top coat is applied on the gauge section part.

Table II. Chemical compositions of the original powders used for top and bond coats (in wt.\%).

\begin{tabular}{|c|c|c|c|c|c|c|}
\hline $\mathrm{ZrO}_{2}$ & $\mathrm{Y}_{2} \mathrm{O}_{3}$ & $\mathrm{HfO}_{2}$ & $\mathrm{MgO}$ & $\mathrm{SiO}_{2}$ & $\mathrm{TiO}_{2}$ & $\mathrm{CaO}$ \\
\hline 90.5 & 7.5 & 1.6 & $<0.01$ & 0.04 & 0.11 & 0.02 \\
\hline \multicolumn{7}{|c|}{ Bond coating powder } \\
\hline Co & $\mathrm{Ni}$ & $\mathrm{Cr}$ & Al & Y & & \\
\hline 38 & 32 & 21 & 8 & 0.5 & & \\
\hline
\end{tabular}

a uniform temperature distribution within $5{ }^{\circ} \mathrm{C}$ along the specimen gauge section at the metal substrate part inside the TBC specimen and an insignificant temperature gradient within $5^{\circ} \mathrm{C}$ between the substrate and top coat. This creep test temperature; $990{ }^{\circ} \mathrm{C}$, corresponds to the average temperature of the substrate, when the TSIT was set up $1280{ }^{\circ} \mathrm{C}$ in the TMF and TGC tests.

During these tests the loading point displacement was continuously monitored by a linear voltage differential transformer (LVDT) installed into the hydraulic test system. In order to determine the deformation behavior during the TMF and TGC tests, the inelastic strain was measured from the change in gauge section length of the specimen, from two optical markers drawn at the edge part of the specimen gauge section. This measurement was periodically carried out after cooling down the specimen to room temperature. During the pure creep test, on the other hand, the deformation of the specimen was monitored continuously by an extensometer.

\section{$\underline{\text { Results }}$}

Some specific behaviors to which special attention should be paid were discovered by the TMF tests. One of them concerned an inelastic deformation of the TBC specimen, and the other was visible damage in the ceramic top coat. In this section, these will be documented.

Inelastic Deformation Behavior under TMF Test with a Significant Temperature Gradient

Figure 5 displayed how the TBC specimens deformed inelastically with the number of thermal cycles in the TMF tests. For the purposes of comparison, the inelastic strain accumulated in the TMF tests are compared with the creep strain measured in creep testing. This has been achieved by considering the dwell time at maximum temperature in the TMF test, Tmax (see the upper abscissa). Here, the creep test temperature was set up so that it approximately corresponded to the average superalloy substrate temperature in the TMF test $\left(990{ }^{\circ} \mathrm{C}\right)$, according to the measurements in Table I.

As shown in Figure 5 (a), when the external stress was zero, neither inelastic deformation nor macroscopic failures of the ceramic top coat was seen in the TBC specimen even after 500 cycles. As documented later, however, it was found that many internal cracks normal to the radial axis were found under this condition. When the external stress was increased to $70 \mathrm{MPa}$ the TBC showed an inelastic strain of $0.5 \%$ after $500 \mathrm{TMF}$ cycles

Table III. Summary of test conditions. Here the specimens were subjected to the thermal cycles in the TMF test, but not in the TGC test (see Figure 3).

\begin{tabular}{|c|c|c|c|c|}
\hline Test & $\begin{array}{c}\text { Maximum } \\
\text { temperature in } \\
\left.\text { TSIT, Tmax. }{ }^{\circ} \mathrm{C}\right)\end{array}$ & $\begin{array}{c}\text { Mimimum } \\
\text { temperature in } \\
\text { TSIT, Tmin. }\left({ }^{\circ} \mathrm{C}\right)\end{array}$ & $\begin{array}{l}\text { Applied stress } \\
(\mathrm{MPa})\end{array}$ & Environment \\
\hline TMF & $1280^{\star \star}$ & $700^{\star \star}$ & $170,100,70,0$ & Combustion gas \\
\hline $\begin{array}{l}\text { Thermally } \\
\text { gradient creep }\end{array}$ & $1280^{\star \star *}$ & $1280^{\star \star \star}$ & 170,100 & Combustion gas \\
\hline $\begin{array}{l}\text { Laboratory } \\
\text { creep }\end{array}$ & $990^{\star}$ & $990^{*}$ & 170,100 & Laboratory air \\
\hline
\end{tabular}

*corresponding to substrate temperature when the specimen was exposed at Tmax in TMF test 

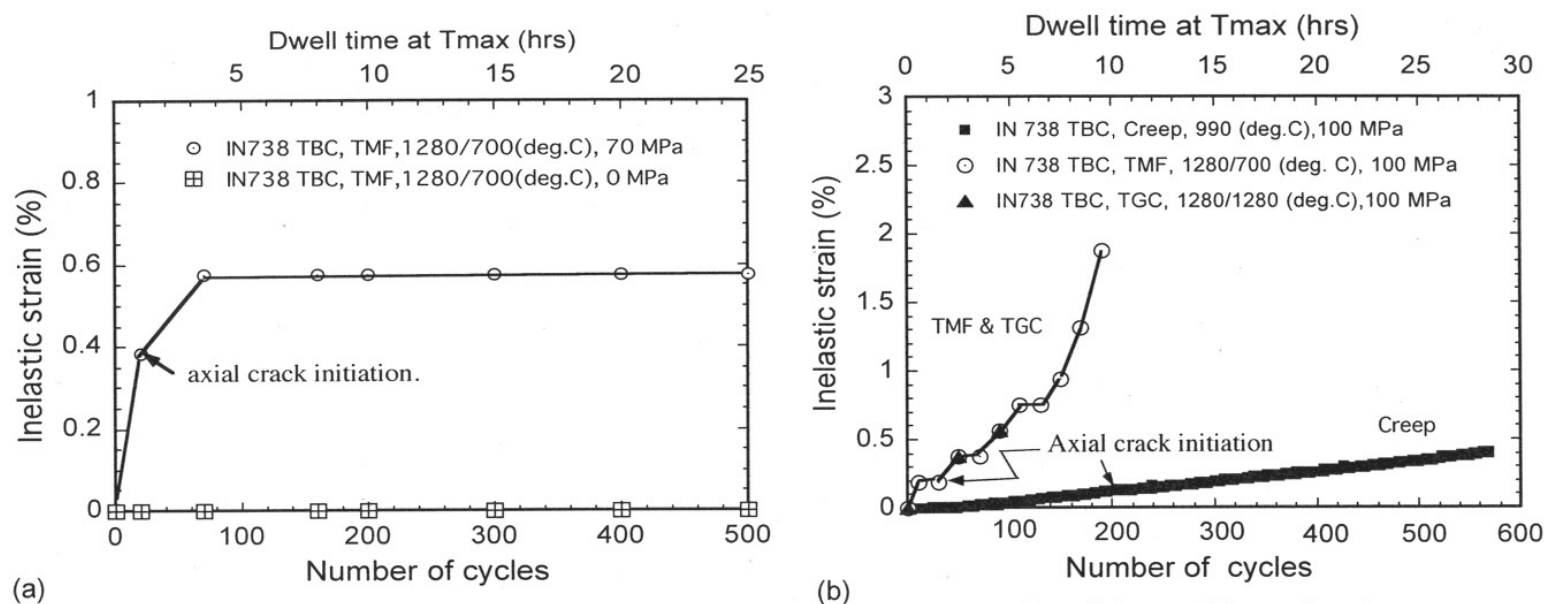

Dwell time at Tmax (hrs)

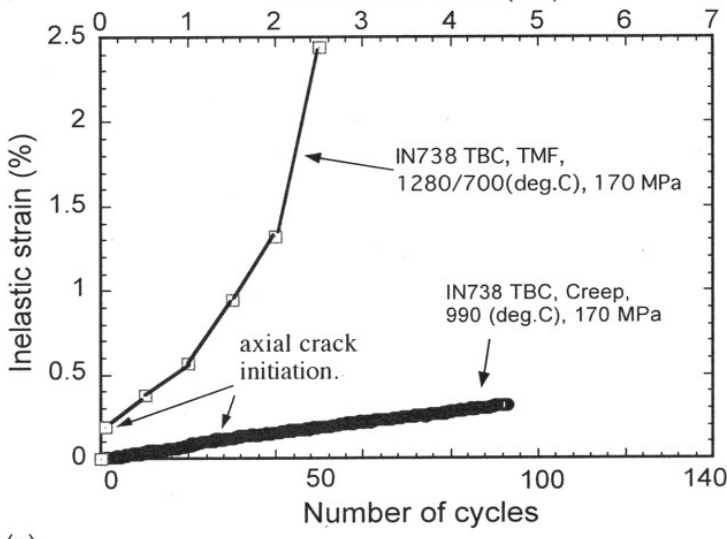

(b)

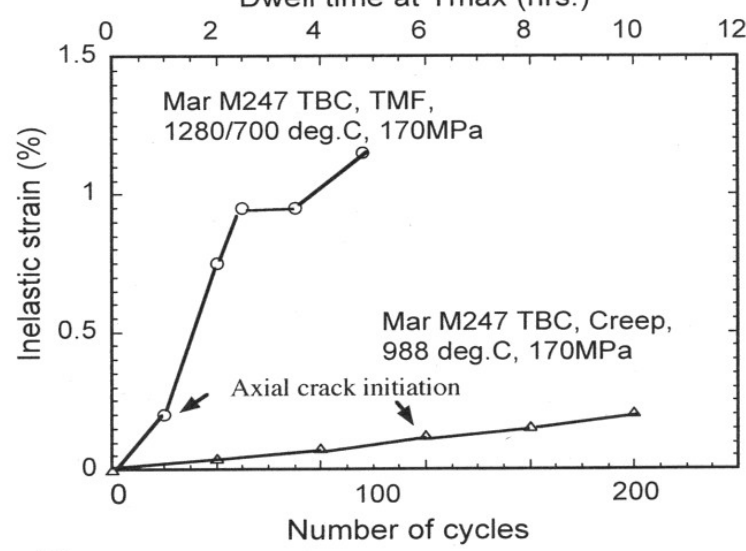

(d)

Figure 5. Comparison of inelastic deformation between the creep, TGC and TMF tests: :(a) IN738 TBC; 70 and $0 \mathrm{MPa}$;

(b) IN738 TBC, $100 \mathrm{MPa}$; (c) IN738 TBC, $170 \mathrm{MPa}$ and (d) Mar M247 TBC, $170 \mathrm{MPa}$

(Figure 5(d)). However, the deformation was not progressive cycle by cycle under this condition (Figure $5(\mathrm{~d})$ ).

When the constant external stress was increased up to $100 \mathrm{MPa}$ in the TMF test, dramatic change appeared in the specimen (Figure 5 (b)). The specimen exhibited a progressive inelastic deformation behavior cycle by cycle, resulting in a final rupture after about 100 cycles. As shown in Figure 5(c), this behavior got more pronounced when the external stress level was increased up to 170 $\mathrm{MPa}$.

The most noteworthy behavior was found from the comparison between the TMF, TGC and simple creep tests. As shown in Figures 5(b) through (d), the inelastic deformation rate was significantly higher in the TMF test, compared with those in the TGC and simple creep tests. This behavior was also observed in the Mar M247 TBC specimen (Figure 5(d)). It is worth reminding the reader that a thermal gradient between the surfaces of the substrate and the bond coat existed in the TGC tests, as in the TMF tests. This implies that not only the temperature gradient inside the specimen but also the repeat of thermal cycles may develop additional damage significantly. This point will be discussed continuously through this work.

\section{Damage Evolution in Ceramic Top Coats}

Figure 6 shows the change in the appearance of the specimen surface with TMF cycle. It is clear that many cracks normal to the loading axis, were produced by the application of the TMF loading. Hereinafter, this type of crack is called "vertical crack". The crack opening displacement of these vertical cracks increased with TMF cycle until finally the top coat spalled off the specimen. It should be noted in Figure 6 that any cracks normal to the hoop direction (hence, parallel to longitudinal direction) were not seen. This suggests that a major driving force of the vertical crack would be a stress induced by external load, and not by internal stress, which will be discussed again in the next section. Figure 7 displays how the number of vertical cracks increases in the specimen gauge section as a function of overall inelastic strain of specimen. It is seen that the axial cracks were pronounced after the specimen strain was beyond a critical value of $0.1-0.2 \%$, which is nearly equal to critical rupture strain of the ceramic top coat [11].

In order to get more quantitative understanding on the vertical cracking behavior, the vertical crack density was measured on the longitudinal cross section of the specimen. The magnitude of 


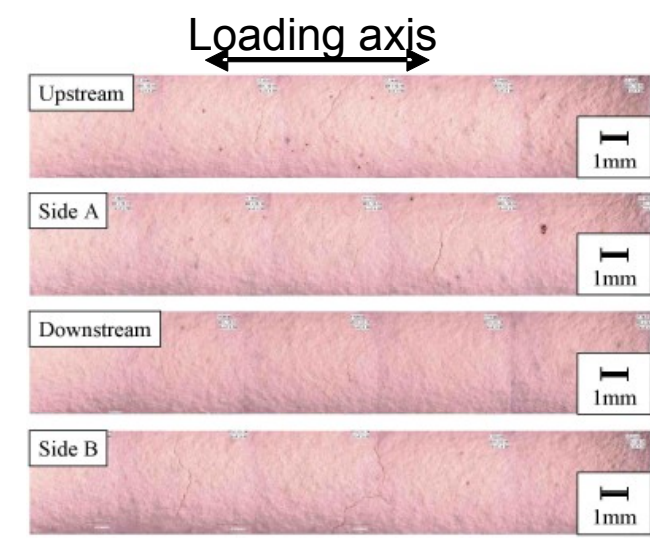

(a)

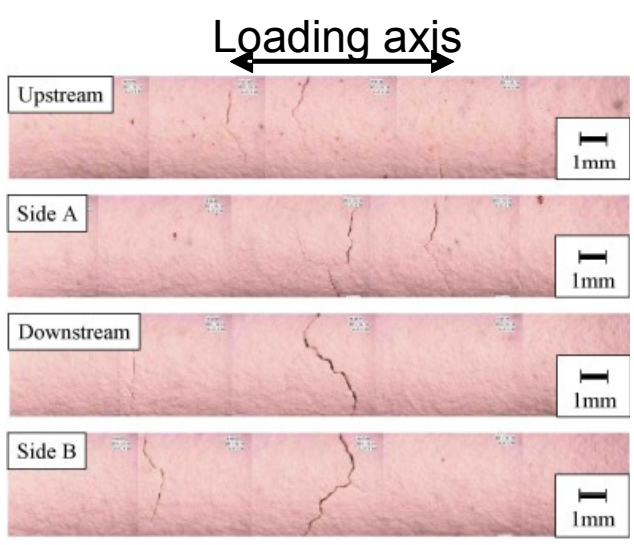

(b)

Figure 6. Change of surface appearance of the TBC specimen with the number of TMF cycles (1280/700 ${ }^{\circ} \mathrm{C}$ TMF, IN738 TBC, $\left.100 \mathrm{MPa}\right)$ : (a) 170 cycles and (b) 190 cycles.

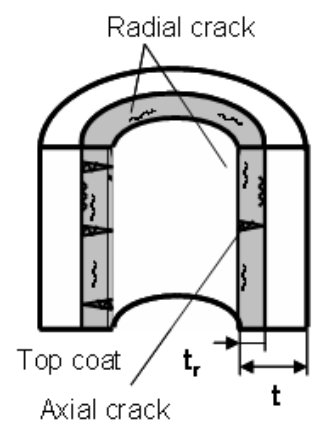

(a)

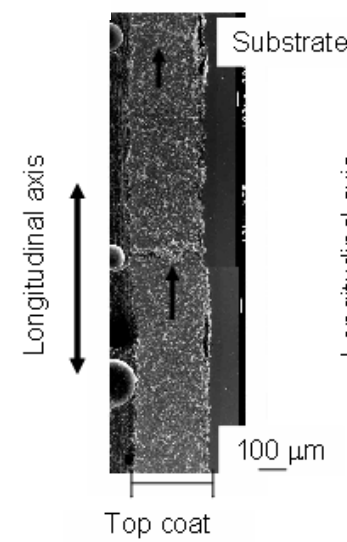

(b) cracking was represented by a line density of the cracking that was measured by an intercept method given by

$$
D v=N v / L
$$

where $\boldsymbol{N} \boldsymbol{v}$ and $\boldsymbol{L}$ are the number of vertical cracks completely through the top coat on the specimen cross section, and the specimen gauge section, respectively. The measurement of $\boldsymbol{D} \boldsymbol{v}$ was carried out on the longitudinal cross section planes parallel and normal to the combustion gas flow: Figures 8 and 9. It was found that the vertical crack density was significantly higher at the downstream site than at the upstream one in a given specimen, while the density at the side area was at a value between them. This trend was commonly seen irrespectively to the magnitude of external stress in the TMF test; compare between four graphs in Figures 9. These results suggest that the vertical cracking might be more preferentially driven from the downstream site; or from the lower temperature site in the TMF test.

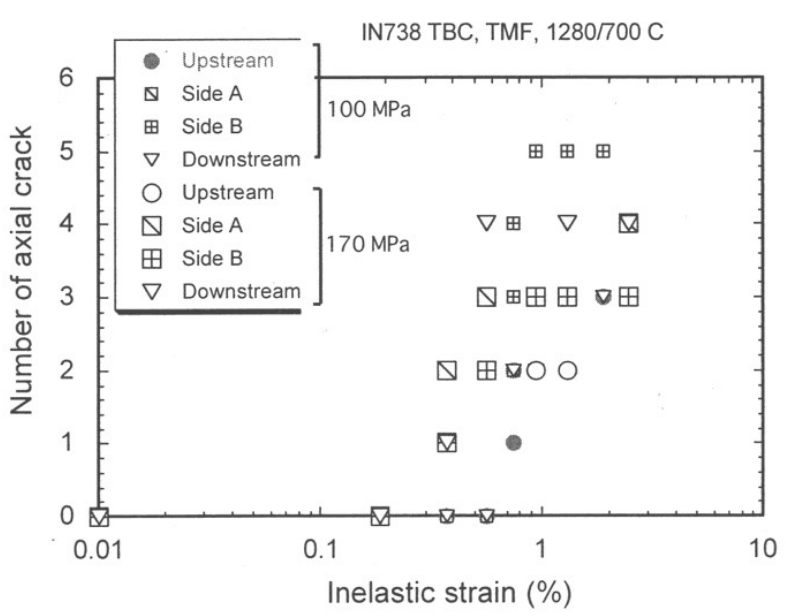

Figure 7. Change in the number of axial cracks with inelastic deformation $\left(1280 / 700^{\circ} \mathrm{C}\right.$ TMF test, IN738 TBC, 100 and $170 \mathrm{MPa}$ ).

Figure 8. Two type of cracks appearing in the top coat: (a) Illustration; (b) Axial crack (IN738 TBC, TMF, $1280 / 700^{\circ} \mathrm{C}$, 200 cycles, $100 \mathrm{MPa}$ ); (c) Radial crack(IN738 TBC, TMF, 1280/700 ${ }^{\circ} \mathrm{C}, 500$ cycles, $0 \mathrm{MPa}$ ). 
The axial cracks were produced not only in the TMF test but also in the TGC and pure creep tests. The crack densities between the three kinds of tests are compared in Figures 9, which show little difference in the overall density between the three tests. However, it should be noted that $\boldsymbol{D} \boldsymbol{v}$ was significantly higher at the downstream side than that at the upstream side in the TGC test, as well as in the TMF test. This result demonstrates that the temperature gradient inside the specimen may assist the axial cracking, which will be discussed again later.

Not only the "vertical crack" but also the other type of cracks were seen in the TMF tests, which were nucleated on the plane normal to the specimen radial direction (and; hence, parallel to the bond/top coat interface): see Figures 8(a) and 8 (c). This type of crack is called a "radial crack" in this work. These cracks were not visible from the specimen surface, but they were discovered only by the observation of the longitudinal section of the TBC specimen.

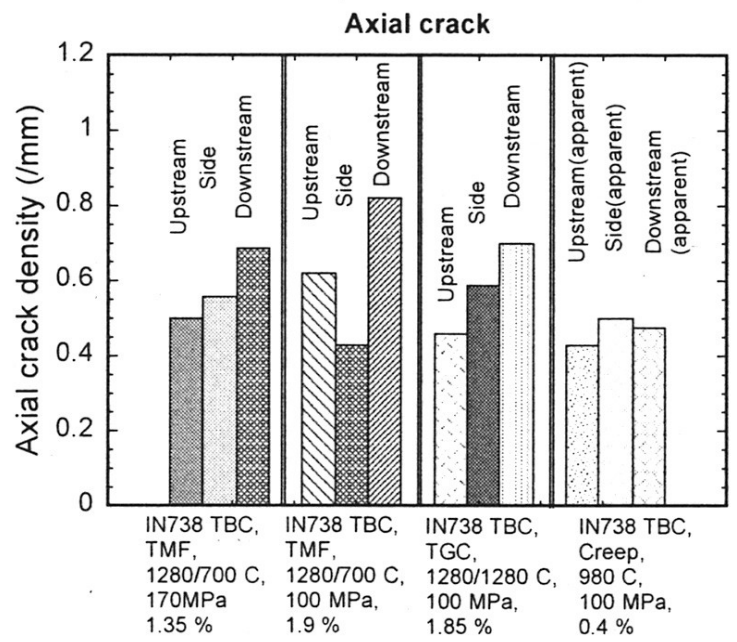

Figure 9. Comparison of axial crack density between the creep, TGC and TMF tests. This figure also suggests which area was the more preferential site for axial cracking.

Radial crack

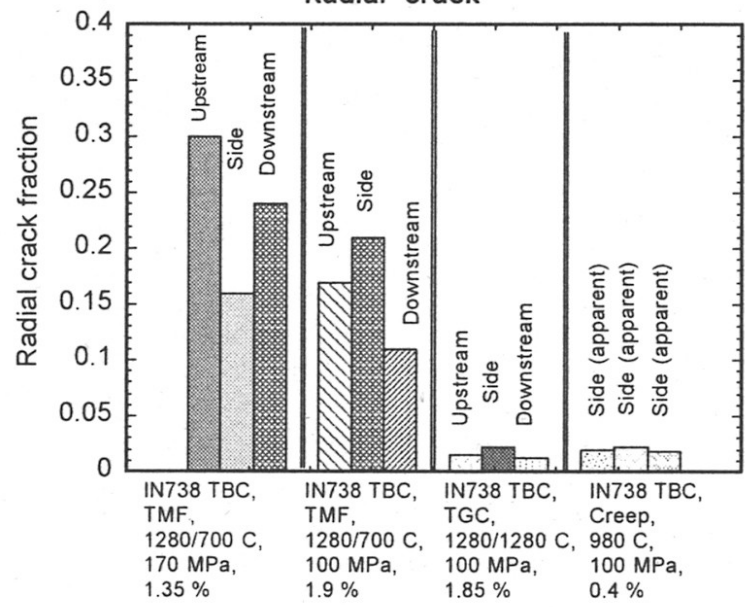

Figure 10. Comparison of degree of radial cracking, given by $t r / t$, between the creep, TGC and TMF tests.
A stress normal to the radial axis of the specimen is essential for the radial cracking. No radial stress is built up in monolithic materials under a uni-axial loading condition. In composite materials, it can be built up from a contribution of Poisson contraction resulting from a difference in elastic moduli between the ceramic top coat and superalloy substrate, even when the specimen is subjected to a uni-axial loading [13]. In this work, however, it is worth noting that the crack shown in Figure 8(c) emanated only by the application of thermal cycles without any external loads. Accordingly, the nucleation of radial cracks did not always need an application of external load in this work, and rather a repeat of internal stress, or thermal stress, resulting from the thermal expansion mismatch between the ceramic top coat and superalloy substrate, must play an essential role there. In the other words, a degree of radial cracking must be a parameter to represent the degree of thermal cycle damage.

The radial cracks were produced non-uniformly through the top coat thickness. However, they were concentrated in a limited thickness neighboring the substrate, $\boldsymbol{t r}$ (gray zone in Figure 8(a)). The magnitude of radial cracks was represented by the fraction, $\boldsymbol{t r} / \boldsymbol{t}$, in this work, where $\boldsymbol{t}$ is total thickness of top coat. Figure 10 expresses how high the magnitude of radial cracking was in the respective tests, which shows that the magnitude of radial cracking was significantly higher in the TMF test, compared with that in the TGC and pure creep test. It is also found from Figure 10 that the magnitude of radial cracking was almost zero in the pure creep test; an indication that the radial stress might be low enough during the pure creep test. Thus, there is a distinguished difference in damage evolution between the TMF, TGC and creep tests, on the basis of the radial cracking. As shown in Figure 10, on the other hand, it is too hard to find a significant difference in the degree of radial cracking between the upstream, side and downstream sites in a given specimen exposed to either TMF or TGC test.

\section{$\underline{\text { Residual Stress in TBC Specimen }}$}

In order to explore the underlining damage mechanisms, both the elastic stiffness of the ceramic top coat and the residual stress built-up in the TBC specimen were measured, as function of isothermal aging time and temperature, which ranged between 0 1000 hrs., and $900-1100{ }^{\circ} \mathrm{C}$, respectively. For this purpose, the isothermal aging was applied to a plate shape TBC specimen using an electric furnace in air. The TBC specimen used was 3.5 $\mathrm{mm}$ thick, $10 \mathrm{~mm}$ wide and $70 \mathrm{~mm}$ in length, with the top coat of $0.5 \mathrm{~mm}$ in thickness, and was prepared by the same process as that documented in the previous Section.

Elastic stiffness of the ceramic top coat, $\boldsymbol{E}_{t c}$, was measured from the stress-strain curve which was monitored during a tensile test on the free-standing $0.5 \times 10 \times 70 \mathrm{~mm}$ rectangular top coat specimen, which was extracted by chemically resolving the metal substrate from the TBCs [11]. The strain of the top coat specimen was measured via a strain gauge directly adhered at the center of specimen gauge section. On the other hand, the residual stress built-up in the ceramic top coat, $\sigma_{r}$, was estimated from the relief strain, $\varepsilon_{\text {relief }}$, that appeared when both the bond coat and the substrate were completely removed from the aged TBC specimen via a chemically removal method. A magnitude of $\sigma_{r}$, was estimated by

$$
\sigma_{r}=E_{c} \varepsilon_{\text {relief }}
$$




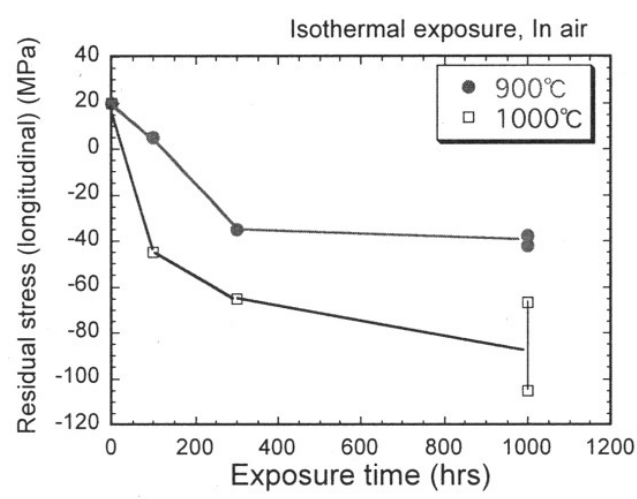

Figure 11. Change in residual stress in the ceramic top coat with isothermal exposure.

Table IV. Summary of mechanical properties of the ceramic top coat.

\begin{tabular}{c|c|c|c}
\hline Material & $\begin{array}{c}\text { Thermal expansion } \\
\text { coefficient }\left(x 10-6 /{ }^{\circ} \mathrm{C}\right)\end{array}$ & $\begin{array}{c}\text { Elastic } \\
\text { modulus }\end{array}$ & Poisson ratio \\
\hline Mar M247 (R.T.) & 15.5 & 185 & 0.25 \\
\hline Mar M247 $\left(600^{\circ} \mathrm{C}.\right)$ & 17.7 & 155 & $0.25^{*}$ \\
\hline Mar M247 $\left(1000^{\circ} \mathrm{C}.\right)$ & 19.5 & 110 & $0.25^{*}$ \\
\hline YSZ top coat $(\mathrm{R} . \mathrm{T})$. & 8.5 & $30 \sim 40$ & 0.15 \\
\hline YSZ top coat $\left(1000^{\circ} \mathrm{C}\right)$ & 12.5 & $30 \sim 40^{*}$ & $0.15^{*}$ \\
\hline
\end{tabular}

where $\boldsymbol{E}_{c}$ is elastic modulus of the top coat. The measurement results of the $\boldsymbol{E}_{t c}$ and $\boldsymbol{\sigma}_{\boldsymbol{r}}$ are summarized in Table IV and Figure 11 , which showed that the modulus significantly increased when the specimen was exposed at high temperature for long time. When the exposure time was long enough, the modulus seemed to be almost saturated. These increases may result from the progress of sintering of the top coat during isothermal exposures $[1,2,11]$. On the other hand, the residual stress in the as-sprayed top coat was almost zero or slightly tensile at room temperature; approximately $30 \mathrm{MPa}$ : see Figure 11 . After being exposed at high temperature, it moved into compressive. When the specimen was exposed for $100 \mathrm{hrs}$. at $1000{ }^{\circ} \mathrm{C}$, the magnitude reached approximately $80-100 \mathrm{MPa}$ in compression. This trend is similar to that observed by other researchers $[1,11]$.

\section{$\underline{\text { Discussion }}$}

\section{Cracking in Ceramic Top Coat}

In the present TMF test the TBC specimens were subjected to external and internal stresses, or thermal stress, as schematically drawn in Figure 12. From the experimental results shown in the previous section, on the other hand, the internal stresses appear to determine the cracking behavior in the ceramic top coat. Here, there are two kinds of internal stresses considered in this work: one is an internal stress resulting from the temperature gradient (Figure 12 (b)), and the other from differences in thermal expansion coefficient between the ceramic top coat and the substrate (Figure 12 (c)).

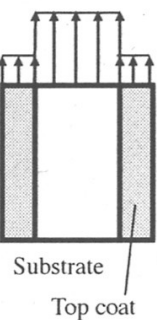

(a) external stress
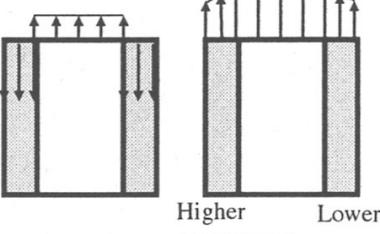

temperature temperature

wall. wall.

(d) Superposition

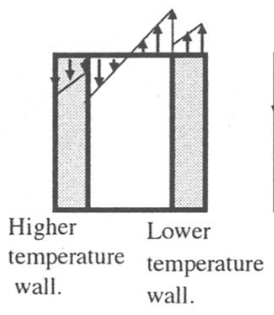

Figure 12. Stress states in the TBC specimens, resulting from external load and some types of internal stresses.

In discussing the mechanism of TMF failure, it is important to estimate a critical temperature from which internal stresses in the ceramic top coat become significant. This temperature is often called the "homologous temperature" [1,13]. The homologous temperature dominates not only the magnitude of stress but also the sign itself. Meanwhile, the thermal expansion coefficient of the top coat was lower than that of the superalloy substrate, as summarized in Table IV. Taking into consideration, it is reasonable to assume that the homologous temperature may be close to the maximum temperature to which the TBC specimens were exposed. This corresponds to the assumption that the internal stress could be approximated by zero during the dwell period at Tmax in the present TMF test, and it would accumulate during cooling. The residual stress in compression, shown in Figure 11, which was measured at room temperature after the isothermal exposure, can be explained by this argument. In addition there is no discrepancy with the experimental observation that the significant radial cracks were nucleated after the thermal cycles (Figure 10), because the sign of radial stress component normal to the bond coat/top coat interface is positive (or in tension) under the above assumptions.

Following the above approximation, the internal stress in the ceramic top was estimated when the TBC specimen was uniformly cooled from $1000{ }^{\circ} \mathrm{C}$ to $600{ }^{\circ} \mathrm{C}$. Here the following analytical expressions were used for the calculation [13], together with the mechanical properties summarized in Table IV.

$$
\begin{aligned}
& \frac{\sigma_{c, z}}{E_{c}}=\frac{\lambda_{2}}{\lambda_{1}} \frac{E_{s}}{E}\left[\frac{V_{s}}{v_{c}}\right] \Omega \\
& \sigma_{r, s,}=-p \\
& \sigma_{\theta, c}=p\left(1+V_{s}\right) / V_{c}
\end{aligned}
$$

with

$$
\begin{aligned}
& \frac{p}{E_{c}}=\frac{1}{2 \lambda_{1}}=\left[\frac{V_{c}}{1-v_{s}}\right] \Omega \\
& \Omega=\left(\alpha_{s}-\alpha_{c}\right) \Delta T
\end{aligned}
$$




$$
\begin{aligned}
& \lambda_{1}=\frac{\beta_{1}}{\left(1-v_{c}\right) \Delta}, \quad \lambda_{2}=\frac{\beta_{2}}{\Delta} \\
& \begin{array}{l}
\Delta=1+v_{s}+\left(v_{c}-v_{s}\right) V_{s} E_{s} / E \\
\beta_{1}=1-\left(1-E / E_{s}\right)\left(1-v_{s}\right) / 2+V_{c}\left(v_{c}-v_{s}\right) / 2 \\
\quad-\left(E / E_{s}\right)\left[v_{s}+\left(v_{c}-v_{s}\right) V_{s} E_{s} / E\right] \\
\beta_{2}=\left[1-\left(1-E / E_{s}\right) / 2\right]\left(1+v_{s}\right)+\left(1+V_{s}\right)\left(v_{c}-v_{s}\right) / 2
\end{array}
\end{aligned}
$$

where $\boldsymbol{\alpha}, \boldsymbol{E}$ and $\boldsymbol{v}$ represent thermal expansion coefficient, Young's modulus and Poisson ratio, and the suffix "s" and "c" given to them correspond to their values of substrate and coating, respectively. $\boldsymbol{\Delta} \boldsymbol{T}$ is temperature difference between both surfaces of the structure being considered. By Eq. (3-1) to Eq.(3-9) the internal stress components in the ceramic top coat were predicted to be,

$\boldsymbol{\sigma}_{z, c} \sim-290 \mathrm{MPa}$ (in compression), $\boldsymbol{\sigma}_{r, c} \sim 25 \mathrm{MPa}$ (in tension),

$\boldsymbol{\sigma}_{\theta, c} \sim-300 \mathrm{MPa}$ (in compression),

under no external loads. It is worthy to note, not only the longitudinal stress component but also the hoop were predicted as negative after the cooling to $600{ }^{\circ} \mathrm{C}$. This calculation estimates such a state that no longitudinal crack normal to the hoop direction may arise since the hoop stress is negative (in compression), which agreed with the experimental observation in Figure 6 where there were no hoop cracks. Thus, the axial cracks might be nucleated during the loading period at Tmax by the external load. The approximation that the internal stress is zero in the top coat on the TBC specimen at the higher exposure temperature, suggests that only the external load was required for cracking at Tmax. When this is the case, there must be no significant differences in the axial crack density in all the tests.

The results in Figure 9 are consistent with this postulation.

\section{Analysis for Characteristic Deformation under the TMF Test.}

It is very important to understand the damage mechanisms and mechanics that occur during TMF testing when there is a significant temperature gradient inside the specimen, because the inelastic deformation rate under the TMF condition was found to be remarkably higher, compared with that without it, or in pure creep, as indicated in the previous section.

As illustrated in Figure 12(b), the thermal stress is built up when there is a temperature gradient. This is also the case, even when there is no ceramic top coat on the substrate surface. According to a simple elastic analysis, thermal stress distributes linearly as a function of position under a linear temperature gradient inside the two dimensional component [15]. The maximum stress appears at the outer surface, which is given by,

$\sigma_{\max }=\frac{6\left(1+v_{s}\right) D_{s} \alpha \Delta T}{\delta^{3}} \cong \frac{\alpha \Delta T E_{s}}{2\left(1-v_{s}\right)}$

where $\boldsymbol{D}_{\boldsymbol{s}}$, and $\boldsymbol{\delta}$ are the bending stiffness of the structure and thickness of the structure being considered, respectively. The other symbols in Eq. (4) follow those defined in Eq. (3-1). The numerical calculation based on Eq. (4), Table I and IV indicates that the magnitude of maximum thermal stress reaches up to about 80-100 MPa in the superalloy substrate surface at the downstream side in the present TMF test. It is worth noting that this stress level is almost comparable to the external stress level applied. Hence, the internal stress can play a significantly role in the deformation of the substrate.

When the material undergoes an inelastic deformation by creep and plastic deformation, the above linear stress distribution is changed, resulting in a relaxation of maximum stress and a redistribution of stress field, as illustrated in Figure 13. However, it is worth noting that, when the component is once released from the above relaxed thermal stress field and then exposed to thermal stress again, the thermal stress field starts again from the elastic state. This situation can be realized in the present TMF test when the thermal cycle was changed from Tmax to Tmin and again to Tmax, since Tmin was low enough that the material behaves fully elastically and the temperature gradient was insignificant during the dwell period at $\operatorname{Tmin}$ (Table I). On the contrary, this state can not be reached in the TGC test in which the superalloy substrate was always exposed to Tmax. From this point of view there is a significant difference between the TMF and TGC test.

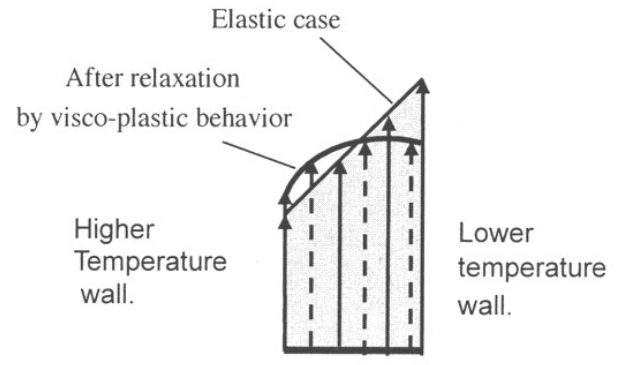

Figure 13. Stress relaxation resulting from visco-plastic deformation of material.

Based on the above, some possible stress states during the present TMF test are schematically displayed in Figures 14, depending on the volume fraction of inelastically deformed region. Here the states are illustrated for a simplified case in which a proof stress is constant through the specimen cross section. The details are as follows.

When the specimen is exposed to $\boldsymbol{T} \boldsymbol{m a x}$ in the TMF test, the superalloy substrate can locally deform inelastically, as a result of thermal stress superimposed on a given external stress. Creep must accelerate this behavior. This state obeys the stress distribution through the wall thickness, as illustrated by the line A-B-C in Figure 14(a). When the specimen is exposed to the dwell period at $\operatorname{Tmin}$ in the TMF test, the specimen should be elastically released from thermal stress and behaves elastically, because the yield stress of the superalloy considered was high enough at $650{ }^{\circ} \mathrm{C}(; \sim 810 \mathrm{MPa}$ in Mar M247, and $780 \mathrm{MPa}$ in IN738, respectively), compared with the external stress level. The resultant stress and strain states are illustrated by the line A'$^{\prime}-\mathrm{B}^{\prime}-\mathrm{C}^{\prime}$ in Figure 14(b), as an idealized model.

When a magnitude of thermal stress induced by temperature gradient is moderate compared with that of external stress, an inelastic deformation is limited only in the first TMF cycle, and the material behaves elastically after the second TMF cycle; 


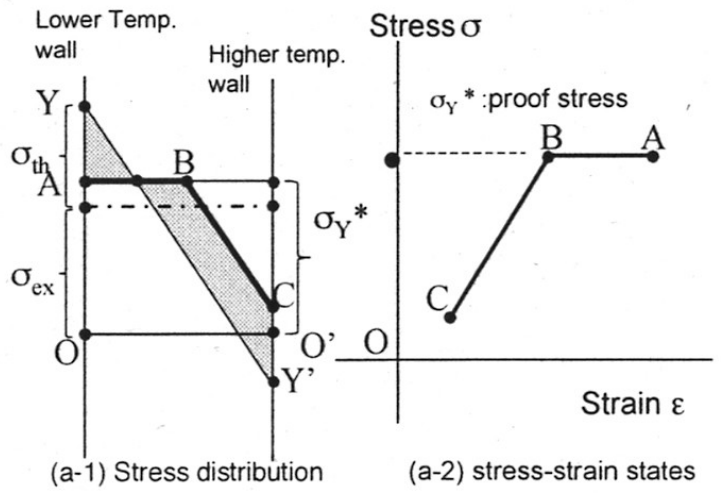

(a)

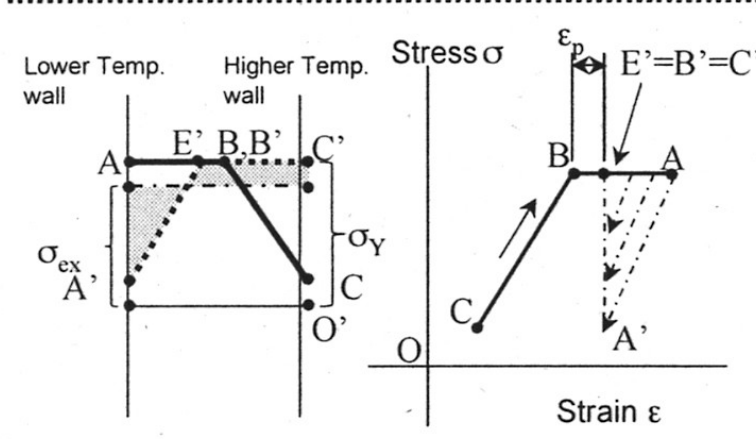

(c-1) Stress distribution

(c-2) stress-strain states

(c)

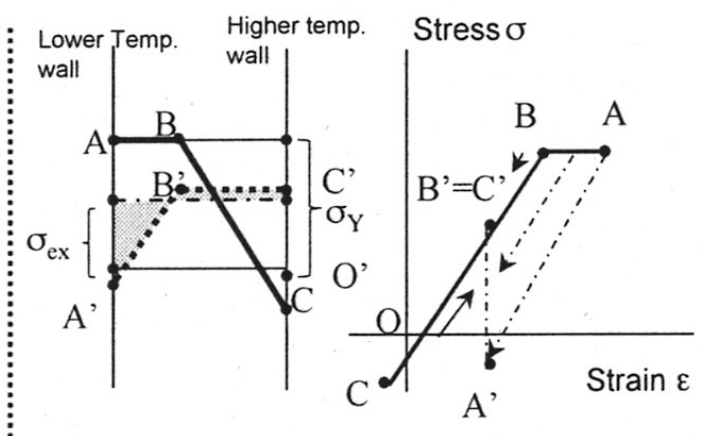

(b-1) Stress distribution

(b-2) stress-strain states

(b)

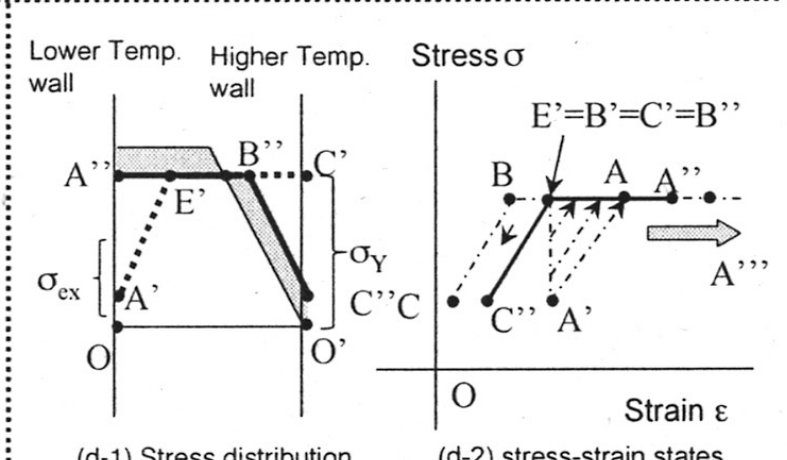

(d-1) Stress distribution

(d-2) stress-strain states

(d)

Figure 14. Stress and strain states when thermal stress is superimposed on external stress. Here the state is illustrated under an idealized condition, assuming the proof stress is constant through the component thickness. The illustrations are drawn referring to Ref. [14]: (a) Local inelastic deformation induced by thermal stress superimposed on external stress during the dwelling period at Tmax.; (b) Released thermal stress during the dwelling period at Tmin, resulting in a shakedown; (c) A stress state at $\boldsymbol{T} \boldsymbol{m i n}$, after severely deformed inelastically during the dwelling period at $\boldsymbol{T} \boldsymbol{m a x}$. in TMF cycle, resulting in a ratcheting and (d) Ratcheting deformation cycle by cycle.

resulting in a shakedown behavior (Figure 14(b)). However, once a critical condition is achieved, the specimen appears to obey a progressive inelastic deformation cycle by cycle after the 2 nd cycle, or a ratcheting deformation, as shown in Figure 14(c) and 14(d). The ratcheting is known as an important phenomenon of concern in nuclear structures [14]. As the mater of fact, these two different states; shakedown and ratcheting behaviors, are evident in Figure 5(a) and Figures 5(b)-(d), respectively.

Assuming a simplified two dimensional component made of a material, which obeys an elastic-perfectly-plastic behavior with a time-independent yield stress, $\sigma_{\mathrm{Y}}$, a transition condition from Figure 14(b) to Figure 14(c) is given such that the inelastically deformed area (the area AB in Fig. 14), is beyond a half of the total thickness of component [14]. From the mathematical calculations, the following criterion is derived for ratcheting and shakedown:

$$
\frac{1}{4} \sigma_{t h}+\sigma_{e x} \geq \sigma_{Y} \text { (ratcheting) }
$$

$$
\frac{1}{4} \sigma_{t h}+\sigma_{e x} \leq \sigma_{Y} \text { (shakedown) }
$$

where $\sigma_{t h}$ and $\sigma_{e x}$ are thermal and external stresses, respectively, and $\sigma_{Y}$ is the proof stress of the substrate. On the other hand, no ratcheting condition is given by;

$$
\sigma_{t h}+\sigma_{e x} \leq \sigma_{Y}
$$

These criteria are summarized in Figure 15; a kind of damage map.

Strictly speaking, $\sigma_{Y}$ is not constant and is influenced by creep and cyclic plastic deformation; hence Eqs. (5) to (7) are no more than tentative equations. However, once $\sigma_{Y}$ is successfully represented by a suitable function of time and stress, the map as illustrated in Figure 15 is expected to be powerful tool in predicting damage mechanisms in thermal barrier coated superalloy structures, which are subjected to significant temperature gradients and TMF cycles. Needless to say further 


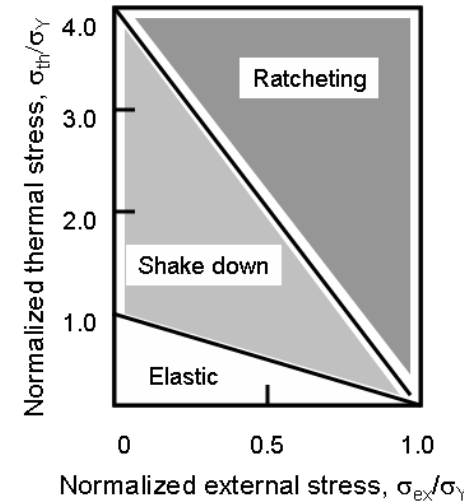

Figure 15. A simplified damage map during the TMF cycles, referring to Ref. [14].

exploration is required to rationalize the damage map more quantitatively.

Meanwhile, thermal stress resulting from the thermal expansion mismatch between the substrate and the ceramic top coat can also contribute to the thermal ratcheting mechanism documented above. However, the stiffness of the top coat of the TBC specimen in this work was low enough, compared with the total stiffness of the present TBC specimen. Thus, it is rational to consider that the specific inelastic deformation that is generated from TMF cycling would be little influenced by the top coat: i.e., it is essentially controlled by the inelastic deformation of the substrate itself.

\section{Conclusions}

Some specific TMF tests were carried out for the thermal barrier coated superalloy specimens under a combined condition in which the external load was superimposed on the thermal cycles in a simulated combustion gas atmosphere, by means of a recently developed test system.

The conclusions are summarized as follows:

(1) The newly developed test systems enable us to evaluate the mechanical properties of superalloys and the TBCs under specific conditions: under complicated TMF cycles, and under a significant temperature gradient inside the specimen in a simulated combustion gas flow environment.

(2) Some specific damage morphologies and the deformation behavior were experimentally discovered under the above specific TMF conditions. As an example, the inelastic deformation rate of the specimen was significantly higher under the specific TMF and the TGC tests than that under simple creep. Thus the temperature gradient inside the specimen was an important factor to be considered.

(3) There were some significant differences in the cracking behavior of the ceramic top coat, among the specific TMF, the TGC, and the pure creep tests. As an example, the degree of radial cracking was more pronounced under the specific TMF tests, compared with those under the latter two. Thus, the application of thermal cycles induces the additional damages from this point of view, as well.

(4) The axial crack density in the ceramic top coat was noticeably higher at the downstream side in the combustion gas flow (i.e., at lower temperature side) than that at the upstream side. From this aspect the temperature gradient was important, as well.

(5) Based on the findings (1) to (4), a mechanistic model was proposed for both the specific failure modes and the inelastic deformation, especially under the TMF condition. The model was summarized into a damage map in terms of some mechanical criteria.

\section{Acknowledgement}

The authors express their gratitude to a financial support by the Grain-in-Aid (A) for Scientific Research by JSPS (No. 21246022).

\section{References}

1. R.A. Miller, Oxidation "Based Model for Thermal Barrier Coating Life," Journal of American Ceramics Society, 67 (1984), 517-521.

2. National Research Council, Coatings for High Temperature Structural Materials - Trends and Opportunities -, (Washington D.C.: National Academy Press, 1996).

3. B.B. Seth, Superalloys: The Utility Gas Turbine Perspective, Superalloys 2000, ed. T. Pollock et al., (Warrendale, PA: TMS, 2000), 3-12.

4. K. Schneider, and H.W. Gruling, "Influence of Coatings and Hot Corrosion on the Fatigue Behavior of Ni-based Superalloys," Thin Solid Films, 84 (1981), 29-36.

5. T. S. Sudrashan, (ed.), Surface Modification Technologies III, (Warrendale, PA: TMS, 1990).

6. Masakazu Okazaki, "The Potential for the Improvement of High Performance Thermal Barrier Coatings," Material Research Society International, 55 (2003), 3-10.

7. T. Xu, M.Y.He and A.G. Evans, A Numerical Assessment of the Duriablity of Thermal Barrier Systems that Fail by Ratchetting of the Thermally Grown Oxide", Acta Acta Materlia, 51, (2003), 3807-3820.

8. A. Rabiei, and A.G. Evans, "Failure Mechanisms associated with Thermally Grown Oxide in Plasma Sprayed Thermal Barrier Coatings," Acta Materialia, 48 (2000), 3936-3950.

9. M. Okazaki et al., "Collaborative Research on ThermoMechanical and Isothermal Low-Cycle Fatigue Strength of NiBase Superalloys and Protective Coatings at Elevated Temperatures in The Society of Materials Science," ASTM Special Technical Piblication 1428, Thermo-Mechanical Fatigue Behavior of Materials", (2003), 180-194.

10. T. Brendel et al., "Temperature Gradients in TMF specimensMeasurement and Influence on TMF Life", Int. J. Fatigue, 30 (2008) 234-240.

11. M. Okazaki et al., "Collaborative Research on Adhesion Strength of Thermal Barrier Coatings in JSMS", Journal of Solid Mechnics and Materials Engineering, 4, (2010), 252-262.

12. D. Zhu, and R.A. Miller, "Thermal Conductivity and Elastic Modulus Evolution of Thermal Barrier Coatings under High Heat Flux Conditions," NASA/TM-1999-209069 (1999).

13. B. Budianski, J. Hutchinson and A.G. Evans., J. Mech. Physc. Solids, 34, (1986) 167-185.

14. F.J. Beer, "Plastic Growth of Pressurized Shell through Interaction of Steady Pressure with Cyclic Thermal Stresses", 340-367, Thermal Stress and Thermal Fatigue, ed. D.J. Litter, (London, Butterworths), 1969).

15. S.P.Timoshenko and J.N. Goodier, "Theory of Elasticity", Chap. 13, (New York, McGraw-hill Publishers), 1970). 